\title{
PROJETAR O LEITOR: NAS ASAS DA LEITURA
}

\section{TO PROJECT THE READER INTO THE WINGS OF READING}

\author{
Amasile Coelho Lisboa da Costa Sousa* \\ Otaiza dos Santos Silva ${ }^{* *}$ \\ Solange Diniz de Oliveira**
}

Resumo: Sabe-se que o incentivo àleitura literária deve ser uma realidade no ambiente escolar. Nesse sentido, dentre outros motivos, a escola deve destacar-se por permitir ao leitor o acesso a diversas culturas e ampliando, assim, o repertório de informações (ANTUNES,2009). Portanto, guiados por essa reflexão, o projeto de extensão "Nas Asas da Leitura" tem como objetivo o incentivo à leitura não só dentro da escola, mas que esse hábito ganhe novos espaços, como por exemplo, o familiar. Sendo, pois, a extensão um elo, que tem o dever de levar o conhecimento produzido na academia até a comunidade, o presente trabalho tem por objetivo relatar a experiência vivenciada por alunos extensionistas do curso de graduação do curso de Letras língua - portuguesa e alunos do ensino médio, através de uma oficina, cujo enfoque foi a leitura do texto poético, realizada durante a Feira Literária de Campina Grande - FLIC em duas escolas públicas na cidade de Campina Grande - PB, no ano de 2018.

Palavras-chave: Leitura. Poesia. Feira literária

\begin{abstract}
It is known that the incentive to literary reading should be distinguished by allowing the reader access to diverse cultures and expanding the repertoire of information. (ANTUNES,2009). So, guided by this reflection, the extension project "NasAsas da Leitura" aims to encourage reading not only within the school, but also in the environment. Extension being a link, which has the duty to bring the knowledge produced in the academic environment to the community, the present work has as objective to report the experience lived by students of the graduation in Portuguese Letters course, and high school students through a workshop focusing on poetic text held during the literary fair Flic in two public schools in Campina Grande-PB.
\end{abstract}

Keywords: Reading. Poetry. Literary Fair

\section{Introdução}

A priori, é dever da escola propiciar aos alunos momentos de reflexão acerca das temáticas que rodeiam a sociedade para que eles tenham posicionamento e criticidade sobre elas. Sendo a literatura um meio para tal e pensando nessas temáticas, a convite de

\footnotetext{
*Mestrado em Letras pela Universidade Federal da Paraíba. Professora titular da Universidade Estadual da Paraíba e chefe de departamento do curso de Letras. Tem experiência na área de Letras, com área de concentração em leitura e escrita. .Email: amasilesousa @ hotmail.com

** Otaíza dos Santos Silva, graduanda do curso de Licenciatura em Letras língua portuguesa pela Universidade Estadual da Paraíba, atualmente é professora da rede privada e dos cursinhos preparatórios para o Enem da UEPB e UFCG. Integra o Projeto de Extensão da UEPB- Nas Asas da Leitura - , no qual desenvolve práticas leitoras com alunos da rede pública de ensino na cidade de Campina Grande Email: otaizasilva@gmail.com.

*** Graduanda do Curso do curso de Licenciatura em Letras língua portuguesa na UEPB. Ministra aulas no Cursinho Solidário - PVS da UFCG. Integra o Projeto de Extensão da UEPB- Nas Asas da Leitura - no qual desenvolve práticas leitoras com alunos da rede pública de ensino na cidade de Campina Grande.Email: solangediniz15@gmail.com
} 
uma das organizadoras da FLIC - Feira Literarária de Campina Grande - que o projeto de extensão pensou na oficina a Experiência com Textos Literários, na qual abordou, dentre outros subtemas, a temática negra e o papel/lugar percorrido pela mulher desde tempos remotos até os dias atuais.

Assim, relataremos a seguir algumas experiências de leitura vivenciadas pelos integrantes do projeto Nas Asas da Leitura com alunos do $1^{\circ}$ ano do ensino médio, em duas escolas públicas na cidade de Campina Grande, em virtude da realização da FLIC (Feira Literária de Campina Grande). Propusemos uma oficina de leitura, com duração de 3 (três) horas, intitulada Vivências literárias, com o objetivo de fazer com que a poesia de escritoras negras adentre as salas de aula como forma de resistência. Vale ressaltar aqui a importância das feiras literárias como forma de incentivar e divulgar a leitura, principalmente, se pensarmos no contexto da escola pública.

\section{Motivação para a leitura do texto literário}

Inicialmente, os integrantes do projeto tinham como objetivo apresentar aos alunos a poesia de autoras negras e discutir acerca do lugar que a mulher ocupa. Para isso, utilizamos a sequência básica de Cosson (2016) em que o autor defende que "as mais bem sucedidas práticas de motivação são aquelas que estabelecem laços estreitos com texto que se vai ler a seguir." (p. 55). Desse modo, antes de introduzirmos a leitura dos textos poéticos, utilizamos a dinâmica dos balões. Colocamos no quadro balões com frases do cotidiano. Observamos que, na maioria das vezes, o preconceito passa despercebido, pois os estereótipos já estão enraizados, impulsionando o número de pessoas intolerantes e preconceituosas. Foram utilizadas expressões como:

- Mulher no volante, perigo constante;

- Menina não brinca de luta;

- Já sabe cozinhar, já pode casar!

- A única coisa que você pilota bem é fogão;

- Uma mulher só é completa quando tem filhos;

A partir da leitura dessas frases, os alunos interagiram e emitiram opiniões contrárias e favoráveis ao tema. Com a discussão, pudemos desconstruir alguns pensamentos conservadores, problematizando e alertando os alunos para o que existe por trás dessas expressões. Inicialmente, percebemos que alguns alunos pareciam tímidos, mas logo demonstraram interesse e interagiram. Buscamos assim, provocar e ouvir o posicionamento dos alunos em torno das frases lidas. Aproveitamos esse momento para levar para os alunos o poema "Um homem não chora", de José Craveirinha, escritor moçambicano, com o objetivo de contrapor aos discursos cristalizados e discutidos com os alunos, conforme podemos ver abaixo:

Um homem não chora

Acreditava naquela história

Do homem que nunca chora.

Eu julgava-me um homem. 


\begin{abstract}
na adolescência
meus filmes de aventuras

pumham-me muito longe de ser

cobarde

na arrogante criancice do herói

de ferro.
\end{abstract}

Agora tremo.

E agora choro.

Como um homem treme

Como chora um homem!

\title{
( José Craveirinha)
}

Esse foi o momento de interação em que os alunos puderam refletir sobre os discursos proferidos no dia a dia. A leitura desse poema fez com que os alunos refletissem sobre jargões que são construídos pela sociedade e reproduzidos no nosso dia a dia, como "Homem não chora", "Mulher é sexo frágil". Aproveitamos esse momento para lembrar nomes de grandes mulheres que se destacaram seja na literatura, no esporte, ou na ocupação de grandes cargos na política. Vale destacar que, embora não estivéssemos preocupados com a estrutura do texto, a preocupação era muito mais com o prazer estético, alguns alunos perceberam que a forma de construção do poema contribuía para a poeticidade e que o modo específico de pontuar o texto é também um elemento responsável pela recepção. Esse foi um momento em que os alunos puderam rever alguns posicionamentos que eles defendiam como "verdades" e agora, na descoberta da leitura, fazer uma reconfiguração de alguns posicionamentos machistas arraigados no nosso cotidiano. Assim, a leitura do poema "Um homem não chora" serviu como porta de entrada para o segundo momento da oficina.

No segundo momento da oficina, fizemos uma exposição de fotos de escritoras negras, como Carolina de Jesus, conhecida pela obra Quarto de despejo, Conceição Evaristo, escritora de grande influência, que tem a literatura como arte da "escrevivência", autora de PonciaVicencio, Poemas de recordação e Olhos dágua e a terceira, Cristiane Sobral, escritora e a primeira atriz negra, graduada em Interpretação Teatral pela Universidade de Brasília, conhecida pelas obras "Não vou mais lavar os pratos", "Terra Negra", "Espelhos Miradouros", "O tapete voador", entre outras. Antes da apresentação dessas escritoras, instigamos os alunos sobre a profissão dessas mulheres. Neste momento, os alunos elencaram profissões como empregada doméstica, dona de casa e merendeira, para as duas primeiras escritoras, mantendo a visão estereotipada do negro e, no caso da última escritora, Cristiane Sobral, alguns alunos a identificaram como atriz ou modelo. Quando indagados por que fizeram essa associação, os alunos admitiram levar em consideração a idade e a beleza. Após toda essa discussão, apresentamos uma breve biografia dessas escritoras e a história de resistência e superação de cada, mostrando que a partir de suas obras e do poder da palavra, as autoras alcançaram êxito, tornaram-se grandes nomes na literatura. Mostramos ainda que apesar de hoje serem reconhecidas como grandes escritoras, a escola ainda oculta a real participação da mulher negra na produção histórica, e cultural do Brasil, fato comprovado na fala dos alunos da escola ao demonstrarem desconhecimento da identidade dessas escritoras. Discutimos o quanto foi difícil e obscuro o caminho para a consagração de cada uma e também relatamos o preconceito vivenciado a cada dia por essas mulheres.

Neste momento, aproveitamos para lembrar a Lei $\mathrm{n}^{\circ} .10 .639 / 2003$ que determina 
a obrigatoriedade da inserção da memória afrodescendente brasileira, nas escolas públicas e privadas de $1^{\circ}$ e $2^{\circ}$ graus. Discussões dessa natureza têm relevância por promover debates sobre a representação do negro como sujeito histórico, social e cultural, desnaturalizando as desigualdades raciais. É nesse contexto que os integrantes do Projeto Nas Asas Da Leitura puderam refletir e ressignificar suas práticas, levando a leitura afrodescendente brasileira para o contexto da sala de aula do ensino médio, atendendo ao que já é, por lei, determinado há quinze anos. Toda a discussão gerou muita reflexão que serviu também como motivação para o terceiro momento - a leitura de poemas.

\section{Lendo poesia}

Por vários momentos, percebemos a falta de intimidade dos alunos com o poema. Em conversas informais com os alunos, pudemos comprovar que o texto poético não fazia parte da rotina dos alunos na escola. Mas, apesar dessa pouca circulação do texto poético na escola, aos poucos, percebíamos que os alunos iam interagindo e demonstrando maior interesse pelo texto literário. Tínhamos um grande desafio: resgatar o prazer pela leitura. E, para isso, buscamos oferecer aos alunos uma aproximação com o texto poético, primeiro através da experiência estética, para só depois, discutirmos as questões sociais postas nos poemas.

Após a breve exposição sobre vida e as obras das escritoras negras, os alunos tiveram contato com uma pequena antologia, contendo poemas, cujo núcleo temático era a representação da mulher negra como forma de resistência. Acreditamos que a utilização da antologia de poemas de escritoras negras no espaço escolar contribuirá para um olhar diferente sobre o negro e sua cultura. Nesse momento, apresentamos algumas obras completas das autoras anteriormente mencionadas, a exemplo dos livros: "Não Vou Mais Lavar Os Pratos", de Cristiane Sobral, e "Quarto de Despejo", de Carolina Maria de Jesus.

Iniciamos assim, uma discussão sobre o resgate da identidade negra, sugerida pelos poemas a serem lidos, com o objetivo de sensibilizar os alunos e conscientizá-los dessa escrita como forma de resistência, na poesia de escritoras contemporâneas. Chamamos atenção também para a ausência do negro na literatura do século XIX.

Iniciamos a leitura em voz alta do poema "Gritaram-me negra", de Victória Santa Cruz, feita por dois integrantes do Projeto Nas Asas da Leitura. Nesse momento, o principal objetivo era que os alunos pudessem apreciar, "sentir" o poema. Era uma fase de vivências muito mais emocionais do que racionais com o texto poético. A esse respeito, Ferrarezi (2017) afirma:

\footnotetext{
o primeiro contato de qualquer pessoa com o texto é de natureza estética, seja uma bula de remédio, seja um rótulo de sabão em pó, seja um romance de Proust. A intermediação estética é a porta de entrada para a construção de novos leitores (p. 28).
}

Após a leitura do poema, iniciou-se uma discussão relativa ao sentido e a beleza do poema. Mostramos que "ler em voz alta é um modo de acertar a leitura, de adequar a percepção a uma realização objetiva" (PINHEIRO, 2018, p.30). Desse modo, devemos ficar atentos ao ritmo na hora da leitura de um poema.

Depois, realizamos várias leituras em voz alta do mesmo poema para que os alunos pudessem perceber diferentes possibilidades de ler o poema, dando expressividade a uma palavra ou expressão, a fim de encontrarmos o melhor ritmo e 
entonação. E assim, os alunos foram, pouco a pouco, encorajando-se e oferecendo para ler o mesmo poema "Gritaram-me Negra".

Dando prosseguimento, dividimos a turma em grupos e pedimos que cada grupo escolhesse um poema da antologia. Cada grupo deveria encontrar o melhor tom, o ritmo para a leitura do poema selecionado, pois sabemos que a forma de ler contribui para a construção de sentido e depois ler em voz alta para os outros grupos. Neste momento, os alunos demonstraram interesse pela atividade e ficaram atentos para a leitura feita pelos outros grupos. Em alguns momentos, parávamos e refletíamos sobre a temática do poema. Vale salientar que acrescentamos à antologia, outros poemas que não seguiam a mesma temática, pois nosso objetivo era despertar o prazer estético e não apenas o conteúdo transmitido. Ademais, devemos compreender ainda que a poesia tem o fim em si mesma.

Descreveremos aqui alguns desses momentos dedicados à declamação dos poemas. Um grupo de alunos selecionou o poema "Casamento", de Adélia Prado. E, nesse momento, demonstraram empenho em procurar encontrar o tom adequado para a leitura, contribuindo para o sentido do poema. Perceberam que o tom mais suave na voz contribuiria para dá fidelidade ao poema. No momento da apresentação, os grupos escutaram atentos e, por vezes, pediam para fazer a leitura novamente. Fato que comprova o envolvimento dos alunos na atividade proposta. Um outro grupo escolheu o poema "Não vou mais lavar os pratos", de Cristiane Sobral, e fizeram uma apresentação dramatizada, seguindo as orientações do primeiro poema lido: "Gritaram-me negra", de Vitória Santa Cruz.. Esse foi um momento de muita reflexão e de muita descoberta. Como se tratava de um poema longo, foram feitas várias leituras até que conseguissem encontrar a melhor possibilidade de falar determinados versos, atentando também para a repetição de determinadas expressões e da necessidade de encontrar o tom mais adequado para o que o poema queria passar. Esse foi um dos poemas que os alunos demonstraram ter gostado mais e resolveram dramatizá-lo, dividindo em partes com os membros do grupo. A leitura desse poema originou uma longa discussão sobre o papel da mulher, e, especificamente, da mulher negra na nossa sociedade, em pleno século XXI. Através da poesia foi possível perceber os papéis socioculturais construídos em torno da mulher negra. Foi discutido ainda que historicamente, ocorreu um processo de marginalização, exclusão e opressão, tomando como referência questões de raça, gênero e classe social, na perspectiva da naturalização da condição subalterna da mulher negra, obrigada a cumprir determinados papeis, funções que se configuram como outras formas de escravidão. Por outro lado, os alunos atentaram para a repetição de alguns trechos no poema, como:

\footnotetext{
Não vou mais lavar os pratos

Nem vou limpar a poeira dos móveis

Sinto muito

Comecei a ler.
}

que retratam a mulher negra que se rebela, contesta e redescobre um novo mundo, a partir do momento que "comecei a ler".

Toda essa mudança é percebida em todo o poema. Instaura-se uma nova era na vida da mulher negra, conforme os versos abaixo podem comprovar:

Depois de tantos anos alfabetizada, aprendi a ler

Depois de tanto tempo juntos

Aprendi a separar

Meu tênis do seu sapato 


\section{Minha gaveta das suas gravatas \\ Meu perfume do seu cheiro \\ Minha tela da sua moldura".}

A leitura da poesia de Cristiane Sobral representa, portanto, um diálogo profundo e intenso sobre a condição da mulher negra. No momento dessas discussões, muitos alunos se identificavam com a poesia de Cristiane Sobral, relatando experiências de vida deles ou de alguém da família. Para reforçar a importância de levar a temática do negro para a sala de aula, como forma de construção da identidade negra, nos valemos do pensamento de Gomes (2004)

\footnotetext{
O mais sério é que, dada a invisibilidade da questão racial na escola, muitas vezes, os educadores e educadoras, ao adotarem tais práticas, sequer percebem que essas salas são formadas por uma grande parcela de alunos negros e pobres. (p. 11)
}

Pensar a identidade negra representa para muitos professores ainda um grande desafio. Mas, não podemos esquecer que é papel da escola construir uma pedagogia da diversidade em que o negro seja visto enquanto sujeito histórico, social e cultural.

Esse mesmo entusiasmo dos alunos foi percebido quando da leitura do poema "Vozes mulheres", de Conceição Evaristo. Esse poema faz parte do Livro "Poemas de recordação e outros movimentos. O título do livro aponta para a questão da memória, como elemento norteador de seus poemas. Em "Vozes mulheres", Conceição Evaristo traduz todo o sentimento de angústia e de sofrimento vivido por ela e por seus antepassados, como podemos comprovar nos versos a seguir:

A voz de minha bisavó

$$
\begin{aligned}
& \text { ecoou criança } \\
& \text { nos porões do navio. } \\
& \text { Ecoou lamentos } \\
& \text { de uma infância perdida. }
\end{aligned}
$$

O eu poético traduz não apenas a voz de um sujeito individual, mas de um coletivo, que traduz o clamor de um povo negro e sofrido, mas, ao mesmo tempo, uma trajetória de resistência de um povo que não esqueceu sua história.

Em outro trecho do poema, temos:

$$
\begin{aligned}
& \text { O ontem- o hoje- o agora. } \\
& \text { Na voz de minha filha } \\
& \text { Se fará ouvir a ressonância } \\
& \text { O eco da vida - liberdade. }
\end{aligned}
$$

vozes que se fundem e que agora não são apenas lamentos, mas representam um fazer coletivo. Todos esses pontos foram abordados após a leitura do poema feita pelos próprios alunos e das suas percepções.

O entusiasmo dos alunos para ler os poemas nos permitiu concluir que se utilizarmos motivações adequadas, poderemos ter práticas de leituras satisfatórias. A esse respeito, compartilhamos com o pensamento de Cosson (2018) de que "uma das principais funções da escola seja justamente constituir-se como um espaço onde aprendemos a partilhar, a compartilhar, a processar a leitura" (p. 36).

Estamos convictos de que essa rápida experiência de leitura de poemas 
contribuiu de forma significativa para despertar nos alunos um novo olhar sobre a poesia. Nesse contexto, o professor deve ter a função de mediador, ser a alavanca propulsora da prática de leitura, tornando-a corriqueira e de deleite.

Segue abaixo a relação dos poemas que fizeram parte da antologia feita pelos integrantes do Projeto Nas Asas da Leitura e trabalhados com os alunos na oficina por ocasião da FLIC.

Casamento - Adélia Prado

Vozes mulheres - Conceição Evaristo

Não vou mais lavar os pratos - Cristiane Sobral

Pixaim elétrico - Cristiane Sobral

Homem não chora José caveirinha

Gritaram-me negra- Victória Santa Cruz 


\section{Considerações finais}

Essa nova perspectiva do texto literário, não mais exclusivo aos cânones literários, contribuiu para que não apenas os integrantes do projeto, mas também, os professores das duas escolas em que atuamos percebessem a necessidade de construção de um saber acerca da literatura negra contemporânea, atendendo as exigências da Lei $\mathrm{n}^{\mathrm{o}}$ 10.639/2003, que determina a obrigatoriedade da inserção da literatura afrodescendente. $\mathrm{O}$ grande entrave parece estar relacionado ao cumprimento de currículos já consolidados, em que o texto literário ainda não faz parte da rotina da maioria das escolas.

Desse modo, a leitura precisa ocupar espaço efetivo na sala de aula, isso só será possível com uma reestruturação curricular, em que se reserve a leitura o que Ferrarezi (2017) denominou de "status de conteúdo curricular" (p. 24). Nesse sentido, entendemos a relevância de um trabalho de leitura como o desenvolvido durante a FLIC, como forma de promover uma aproximação entre os leitores e o universo do texto literário.

No entanto, temos consciência de que a presença das oficinas nas escolas é temporária e que, no dia a dia, a escola deve assumir a função de ampliar a capacidade leitora dos alunos através de estratégias de leitura que ultrapassem as amarras de programas preestabelecidos.

\section{Referências}

ABREU, Márcia. Cultura letrada: literatura e leitura. São Paulo: Editora UNESP, 2006)

BRITO, Angela Maria Benedita B. de. et al. (Org.). KuléKulé: Educação e identidade negra.

CADEMARTORI, Lígia. O professor e a literatura: para pequenos, médios e grandes. Belo Horizonte: Autêntica Editora,2012.

COSSON, Rildo. Círculo de leitura e letramento literário. São Paulo: Contexto, 2018.

Letramento literário: teoria e prática. São Paulo: Contexto, 2016.

FERRAREZI, J. R. Celso. De alunos a leitores: o ensino da leitura na educação básica. São Paulo: Parábola Editorial, 2017.

GOMES, Nilma Lino. Educação e identidade negra. In: BRITO, Ângela Maria Benedito B, SANTANA, Moisés de Melo e CORREIA, Rosa Lúcia L. S. (ORG.) Kulé, Kulé: educação e identidade negra. Maceió: EDUFAL, 2004

MARIA, Luzia de. O Clube do livro: ser leitor, que diferença faz? São Paulo: Global, 2016.

PINHEIRO, Hélder e NÓBREGA, Marta. Literatura e ensino: aspectos metodológicos 
e críticos. Campina Grande: EDUFCG,2014.

PINHEIRO, Hélder. Poesia na sala de aula. São Paulo: Parábola, 2018.

SANTIAGO, Ana Rita. Vozes literárias de escritoras negras. Cruz das Almas/ Bahia: UFRB, 2012.

SANTOS, Luis Carlos, GALAS, Maria e TAVARES, Ulisses (orgs).O negro em versos. São Paulo: Moderna, 2005.

SOBRAL, Cristiane. Não vou mais lavar os pratos. Brasília, Editora Garcia, 2016.

YUNES, Eliana. (org). Pensar a leitura: complexidade. Rio de Janeiro: Ed. PUC- Rio de Janeiro: Loyola, 2002.

Recebido em 20 de janeiro de 2019

Aceito em 15 de fevereiro de 2019 